\title{
Special Role of Biological Courses During the COVID-19 Pandemic: Relieving Students'Anxiety
}

\author{
Chang Chen \\ College of Chemical Engineering, Beijing University of Chemical Technology, Beijing 100029, China \\ Corresponding author: chenchang@mail.buct.edu.cn
}

\begin{abstract}
The COVID-19 crisis is having a devastating effect on the education and training of young people by the closing of schools and universities. During COVID-9 pandemic, undergraduate students not only have to adapt to remote learning environment but also withstand huge psychological shocks and pressures, experience nervousness, fear, anxiety, depression, and other psychological problems. Therefore, teachers need to pay due attention and provide appropriate intervention. Biological courses, as important compulsory courses for bio-related disciplines and the elective courses offered to first- and second-year undergraduates, thus bear essential responsibilities. Biological courses should strengthen education on how humans have successfully overcome infectious diseases in history so as to build confidence against the pandemic, reduce students' anxiety and fear, and establish the correct concept of protection. Teachers should also help students realize the importance of biological knowledge in the process of fighting the disease, enhance their motivation and interests of learning, and improve teaching effectiveness. Biological courses should and are possible to play a more important role to help students reestablish their confidence against COVID-19 pandemic.
\end{abstract}

Keywords: COVID-19, Biological courses, Re-establish the confidence, Against pandemic.

DOI: $10.7176 / \mathrm{JEP} / 12-10-04$

Publication date: April $30^{\text {th }} 2021$

The sudden outbreak of COVID-19 pandemic has profoundly affected the lives of everyone in the world (Thomas 2020; Jiang et al. 2020). Colleges and universities have to temporarily close the campus, teachers of all courses have to update the original teaching methods and content, and carry out teaching work through distance teaching, which poses a challenge for teachers and students (Procko et al. 2020). Teachers should realize that for students, they not only need to face changes in learning environment and learning methods, but also have to withstand huge psychological shocks and pressures (Huckins et al. 2020). Investigations indicated that some students have experienced nervousness, fear, depression, and other psychological problems due to self-isolation, infections, and even deaths around them (Huckins et al. 2020). Things get worse when their parents resume work, the students are left at home alone, suffering from loneliness and anxiety (Zhai \& Du 2020). Therefore, teachers need to pay due attention and provide appropriate intervention.

Biological courses are not only important compulsory courses for bio-related disciplines, such as bioengineering, bioscience, pharmaceutical engineering, biomaterials, and biomedicine, but also the elective courses offered to the first- and second-year undergraduates and thus bear important responsibilities. In the epidemic situation, the teaching of biological courses needs to be at the forefront, passing on its own online teaching methods and experiences to other follow-up professional courses. More importantly, it could help to alleviate students' anxiety, tension, and fear by popularizing professional knowledge via online teaching. The first- and second- year students are relatively young, their psychology is not yet mature, their professional knowledge not enough, their understanding of viral diseases insufficient, and they are more likely to feel helpless in the face of the impact of the epidemic. In view of this situation, biological courses should strengthen education on how humans have successfully overcome infectious diseases (such as smallpox, poliomyelitis, plague, malaria, schistosomiasis, etc.) in history to build confidence against the epidemic, reduce students' anxiety and fear, and establish the correct concept of protection. Teachers can also take examples from important discoveries in medical research (such as: Human Genome Project, antibiotics, anti-tumor drugs, etc.) (Chen 2020) to help students realize the importance of biological knowledge in the process of human overcoming disease, enhance their motivation and interests of learning, and improve teaching effectiveness. In future, more researches and teaching reforms are necessary to be carried out to develop novel ideas and methodologies in biological courses for helping students all over the world overcome the COVID-19 crisis.

\section{Acknowledgements}

The authors would like to thank the support given by the Talent Training and Teaching Reform Project from the Beijing Municipal Education Commission and the Teaching Reform Program in Undergraduate Education (2018BHDJGY02), Beijing University of Chemical Technology, China. 


\section{References}

Thomas, J. D. (2020), "Pandemic as Teacher-Forcing Clinicians to Inhabit The Experience of Serious Illness", New England Journal of Medicine 383(4), 306-307.

Jiang, S.B., Shi, Z. L., Shu, Y. L., Song, J. D., Gao, G. F., Tan, W. J. \& Guo, D. Y. (2020), “A Distinct Name is Needed for The New Coronavirus", The Lancet 395(10228), 949.

Procko, K., Bell, J. K., Benore, M., Booth, R. E., Victoria, D. G. M., Dries, D., Martin, D. J., Mertz, P. S., Offerdahl, E., Payne, M. A., Vega, Q. C. \& Provost, J. (2020), "Moving Biochemistry and Molecular Biology Courses Online in Times of Disruption: Recommended Practices and Resources- A Collaboration with The Faculty Community and ASBMB”, Biochemistry and Molecular Biology Education 48, 421-427.

Huckins, J., DaSilva, A. W., Wang, W. C., Hedlund, E. L., Rogers, C., Nepal, S. K., Wu, J. L., Obuchi, M., Murphy, E., Meyer, M. L., Wagner, D. D., Holtzheimer, P. E. \& Campbell, A. T. (2020), "Mental Health and Behavior of College Students during The Early Phases of The COVID-19 Pandemic: Longitudinal Smartphone and Ecological Momentary Assessment Study", Journal of Medical Internet Research 22(6), e20185.

Chen, C. (2020), "Practice of Teaching Reform in Biochemistry under The Engineering Education Accreditation Background", Biology Teaching in University 10(1), 8-11.

Zhai, Y. \& Du, X. (2020), “Addressing Collegiate Mental Health Amid COVID-19 Pandemic", Psychiatry Research 288, 113003. 